\section{Microcarcinoid tumor diagnosed with high- resolution magnification endoscopy and narrow band imaging}

A 63-year-old patient presented with persistent dyspepsia. Endoscopy revealed an $8-\mathrm{mm}$ nodule on the anterior wall of the greater curvature in the proximal part of the body of the stomach. Histological analysis demonstrated a well-differentiated tumor showing positive immunostaining with chromogranin with a background mucosa showing features of atrophic gastritis. Gastric $\mathrm{pH}$ and fasting serum gastrin levels were elevated. A diagnosis of a type I carcinoid tumor was made. The patient then underwent endoscopic mucosal resection with complete resection of the lesion. Follow-up endoscopy 3 months later showed a scar at the previous resection site. However, a diminu-

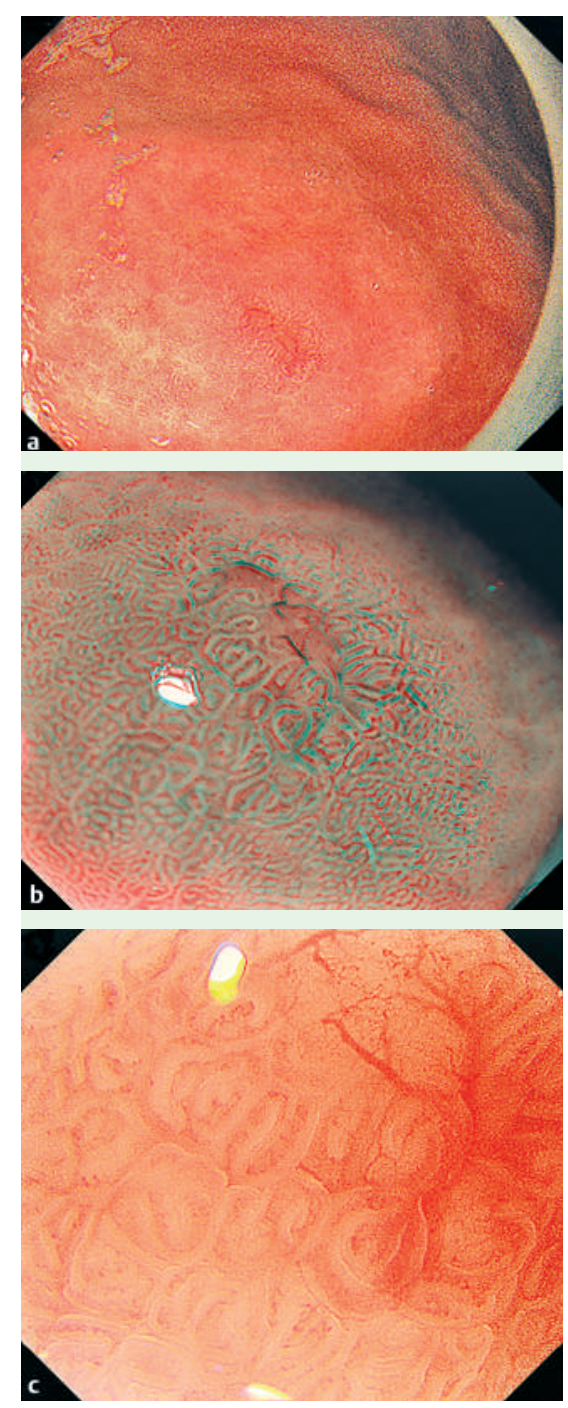

tive, flat, reddened lesion measuring less than $3 \mathrm{~mm}$ with the appearance of an erosion was detected at a separate site on the posterior wall of the greater curvature (๑ Fig. 1a). Narrow-band imaging demonstrated that, at the center of the lesion, the pit structure had disappeared (๑ Fig. 1b). Magnification endoscopy with white light revealed that the subepithelial capillary network was well preserved, but underneath the epithelium, a faint yellowish hue could be seen (ه Fig. 1c). These findings were distinctly different from those of a gastric erosion or a minute gastric carcinoma. In an erosion dilated subepithelial capillaries are seen, and in the center of the erosion whitish inflammatory exudates will be visualized [1]. On the other hand, a flat early carcinoma would exhibit proliferation of the subepithelial capillaries, which would be irregular in both caliber and tortuosity [2]. Taking into consideration the patient's previous history, we suspected the lesion could have originated from an endocrine nest/microcarcinoid [3] which had grown just beneath the epithelium. The histopathological analysis of the lesion revealed a minute carcinoid tumor ( $\bullet$ Fig. 1d). This case illustrates the differential diagnosis between three lesions which appear very similar: an erosion, a flat early carcinoma, and a minute carcinoid, and shows the utility of high-resolution magnification endos- copy with narrow-band imaging in differentiating them.

Endoscopy_UCTN_Code_CCL_1AB_2AD_3AB

\author{
R. Singh, K. Yao, G. Anagnostopoulos, \\ P. Kaye, K. Ragunath \\ Wolfson Digestive Diseases Centre, \\ University Hospital, Queen's Medical \\ Centre, Nottingham, UK
}

\section{References}

1 Yao K, Iwashita A, Kikuchi Y et al. Novel zoom endoscopy technique for visualizing the microvascular architecture in gastric mucosa [review]. Clin Gastroenterol Hepatol 2005; 3 (7 Suppl 1): S23 - 26

2 Yao $K$, Iwashita A, Tanabe $H$ et al. Novel zoom endoscopy technique for diagnosis of small flat gastric cancer: a prospective, blind study. Clin Gastroenterol Hepatol 2007; 5: 869-78

3 Nojiri T, Ikegami M. Multiple minute carcinoids in type A gastritis: attempt at 3-D reconstruction. Pathol Int 2001; 51: 504-510

\section{Bibliography}

DOI $10.1055 / \mathrm{s}-2007-995393$

Endoscopy 2008; 40: E12-E12

(c) Georg Thieme Verlag KG Stuttgart · New York . ISSN 0013-726X
Corresponding author
R. Singh, MRCP
Wolfson Digestive Diseases Centre
University Hospital
Queen's Medical Centre
Nottingham
NG7 2UH
United Kingdom
Fax: +44-115-9249924
rajvindersingh2003@yahoo.com 